OPEN ACCESS

Edited by:

Paolo Fiorina,

Harvard Medical School, United States

Reviewed by:

Moufida Ben Nasr,

University of Milan, Italy

Vera Usuelli,

University of Milan, Italy

*Correspondence:

Alexandrina Burlacu

sanda.burlacu@icbp.ro

Specialty section: This article was submitted to Immunological Tolerance and Regulation,

a section of the journal

Frontiers in Immunology

Received: 20 April 2021

Accepted: 16 July 2021

Published: 03 August 2021

Citation:

Marinescu C-I, Preda MB,

Neculachi CA, Rusu EG, Popescu S and Burlacu A (2021) Identification of a Hematopoietic Cell Population Emerging From Mouse Bone Marrow With Proliferative Potential In Vitro and Immunomodulatory Capacity.

Front. Immunol. 12:698070. doi: 10.3389/fimmu.2021.698070

\section{Identification of a Hematopoietic Cell Population Emerging From Mouse Bone Marrow With Proliferative Potential In Vitro and Immunomodulatory Capacity}

\author{
Catalina-lolanda Marinescu, Mihai Bogdan Preda, Carmen Alexandra Neculachi, \\ Evelyn Gabriela Rusu, Sinziana Popescu and Alexandrina Burlacu*
}

Laboratory of Stem Cell Biology, Department of Regenerative Medicine, Institute of Cellular Biology and Pathology "Nicolae Simionescu", Bucharest, Romania

There is continuing interest in therapeutic applications of bone marrow-derived mesenchymal stromal cells (MSC). Unlike human counterparts, mouse MSC are difficult to propagate in vitro due to their contamination with adherent hematopoietic cells that overgrow the cultures. Here we investigated the properties of these contaminating cells, referred to as bone marrow-derived proliferating hematopoietic cells (BM-PHC). The results showed that both $\mathrm{BM}-\mathrm{PHC}$ and $\mathrm{MSC}$ had strong immunomodulatory properties on T cells in vitro, with PGE2 and NO involved in this mechanism. However, BM-PHC were stronger immunomodulators than MSC, with CCL-6 identified as putative molecule responsible for superior effects. In vivo studies showed that, in contrast to BM-PHC, MSC endorsed a more rapid xenograft tumor rejection, thus indicating a particular context in which only MSC therapy would produce positive outcomes. In conclusion, bone marrow contains two cell populations with immunomodulatory properties, which are valuable sources for therapeutic studies in specific disease-relevant contexts.

Keywords: mesenchymal stromal cells, Ly-6C, bone marrow-derived proliferating hematopoietic cells, CCL-6, immunomodulation

\section{INTRODUCTION}

There has been a continuing interest in the potential therapeutic applications of adult stem-like cells, referred to as mesenchymal stromal cells (MSC). These cells, residing in almost all postnatal organs and tissues, are heterogenous populations of fibroblast-like cells and have initially drawn attention due to their capacity to support hematopoiesis and differentiate into specific cell types (14). Within the bone marrow, MSC are known to reside in a complex microenvironment and together with hematopoietic stem cells (HSC) form a unique bone marrow niche (5, 6). HSC produce all blood cell lineages during homeostasis and stress in a highly dynamic program being tightly regulated by an interdependent network with MSC (5).

Abbreviations: MSC, mesenchymal stromal cells; BM-PHC, bone marrow-derived proliferating hematopoietic cells. 
Among the various types of stem cells proposed for cell therapy (7), MSC were shown to have distinct advantages, which include convenient isolation (MSC can be rapidly obtained from bone marrow and adipose tissue by noninvasive methods), reduced immunogenicity, lack of ethical controversy, and trophic activity $(8,9)$. Although larger than other stem cells used in cell therapy, MSC can trigger the outcomes with no need of homing to the site of injury, as recent studies pointed towards a remote blood-borne-mediated pathway activated by transplanted MSC (10-13).

In preclinical settings, MSC demonstrated consistent ability to promote tissue healing, modulate inflammation and improve the outcomes in various animal models (14). All these positive in vivo effects are primarily due to a broad array of secreted bioactive factors, collectively referred to as MSC secretome, as it is now generally accepted that transplanted MSC do not survive for long in vivo $(15,16)$. The recognition that MSC create a microenvironment suitable for tissue repair has increased the interest in MSC therapy and this interest has been even fueled over the past years by multiple studies showing strong immunomodulatory properties $(17,18)$ with the principal effector being potent inhibition of $\mathrm{T}$ cell function $(19,20)$. Today, MSC are recognized as promising agents for the treatment of inflammatory disorders due to their immunomodulatory functions in contexts linked to auto/allo-immunity $(21,22)$.

Several mechanisms of immunomodulation have been proposed for bone marrow-derived MSC isolated from multiple species. Among these, MSC are capable of educating B cells and inducing regulatory B cell production (23). MSC can also polarize the responses of macrophages from a proinflammatory to an anti-inflammatory/reparative phenotype (24). They can also function to prevent the maturation of dendritic cells and the lytic ability of natural killer cells (1). Concisely, MSC could have extensive interactions with every major component of the innate and adaptive immune system, through a combination of wide-ranging molecular mechanisms involving paracrine activity, extracellular matrix remodeling, direct contact-based signaling, or extracellular vesicles (25). Identifying the particular molecules contributing to the positive effects in each clinical scenario is important for accelerating the transition into clinical practice, which is still considerably difficult.

Their heterogeneity and the absence of a specific MSC-defining antibody make these cells difficult to characterize. Therefore, mouse MSC are currently defined by using a panel of acceptable surface markers (including Sca-1, CD44, CD105), plastic adherent fibroblast-like growth and functional properties $(26,27)$. Besides, owing to the limited amount of these cells in the adult mouse, most of our knowledge of the biological properties of MSC has been obtained from the study of in vitro expanded MSC, rather than of endogenous (or primary) cells (22). Even so, while human and rat MSC are relatively easily obtained in vitro, the expansion of their mouse counterparts is far more difficult. Numerous reports documented that mouse bone marrow-derived MSC are frequently contaminated by hematopoietic progenitors that overgrow the culture during the initial passages. As a result, several strategies to deplete the contaminating cells and purify MSC cultures have been developed by various laboratories (28-32).

In this paper, we comparatively analyzed cells within MSC culture at different passages: an initial passage, at which the hematopoietic cells were prevailing, and two advanced passages, at which MSC culture was free of hematopoietic cells. We showed that both MSC and hematopoietic cells had high immunomodulatory effects on splenic T cells in vitro. Analysis of the secretome produced by these cells and inhibitory studies revealed both common and particular molecules involved in their effects. Our data showed that while both cell types had strong immunomodulatory effects on $\mathrm{T}$ cells in vitro, they were differing in other modulatory properties, such as anti-tumor effect in vivo.

\section{MATERIALS AND METHODS}

\section{MSC Isolation}

MSC were isolated as previously reported (28). Briefly, bone marrow aspirate was obtained from 6 -week-old C57Bl/6 mice by flushing the medullar channels of the tibiae and femurs with $5 \mathrm{ml}$ culture medium (DMEM containing 10\% MSC-qualified FBS) using a syringe with a 26-gauge needle. A single cell suspension was thereafter obtained by passing the aspirate through increasing needle gauges (from 21 to 25), which was subsequently seeded on $10-\mathrm{cm}$ cell-culture treated Petri dish and incubated at $37^{\circ} \mathrm{C}$ under $5 \% \mathrm{CO}_{2}$ atmosphere. The first two passages were performed at around 7-day intervals, by using $0.25 \%$ trypsin and gentle scraping with the rubber policeman. Recovered cells were plated at 5000 cells $/ \mathrm{cm}^{2}$. Starting from the third passage, the cells were trypsinized when reached around $80 \%$ confluency, without using the rubber policeman, and replated on $0.1 \%$ gelatin-coated plates at 5000 cells $/ \mathrm{cm}^{2}$.

\section{Flow-Cytometry}

Cells were trypsinized to obtain a single cell suspension and the density was adjusted to $10^{6}$ cells $/ \mathrm{ml}$. One hundred- $\mu$ l cell suspension was incubated with fluorescent-labeled antibody specific for CD45, Sca-1, CD44, CD29, CD90, CD73, CD105, CD11b, F4/80, CD206, Ly-6C, alone or in combination. All antibodies were purchased from BioLegend. After 30 minutes of incubation at $4^{\circ} \mathrm{C}$, the cells were washed by centrifugation and resuspended in FACS buffer (PBS containing 2\% fetal bovine serum) for flow cytometry analysis. Propidium iodide $(0.2 \mathrm{ug} / \mathrm{ml}$ final concentration) was added before analysis to identify the live cells and at least 30,000 events were considered for each sample. Acquired data was analyzed using CytExpert software (Beckman Coulter). For multiple staining, the compensation matrix was obtained using compensation beads (Thermo Fisher Scientific) combined with fluorescent antibodies for every single-color sample.

\section{Suppression of T-Cell Proliferation by MSC}

To assess the ability of MSC to suppress T-cell proliferation, splenic $\mathrm{T}$ cells were isolated by nonadherence to nylon (33). T cells were CFSE-labeled and then co-cultured for three days with 
anti-CD3/CD28 activating microbeads (in a cell: bead ratio of $1: 1$ ) in 96 -well tissue culture plates at $10^{5}$ cells per well in the presence or absence of irradiated MSC. Various numbers of MSC (ranging from 625 to 10,000 cells/well) were used to assess their immunosuppression capacity. MSC irradiation was performed 24 hours prior to the interaction with $\mathrm{T}$ cells, as previously described (34). The co-culture was maintained for three days, after which the proliferation of the fluorescent cells was analyzed using CFSE dye dilution assay and ModFit software. In experiments assessing various molecules as potential inhibitors for MSC immunosuppressive effect, these molecules were added simultaneously with the lymphocyte suspension at the time of co-culture initiation.

\section{Cytokine Array}

The profiles of the relative levels of cytokines in the conditioned medium produced by MSC culture at low and high passages were analyzed using Proteome Profiler Mouse XL Cytokine Array (R\&D Systems). Briefly, the conditioned medium was incubated overnight with the array, followed by a wash step and incubation with a cocktail of biotinylated detection antibodies. StreptavidinHRP and chemiluminescent detection reagents were then applied, and the signal produced at each spot (corresponding to the amount of protein bound) was detected with FUJIFILM Luminescent Image Analyzer LAS-3000. The pixel densities were analyzed with TotalLab Quant software.

\section{LEGENDplex Assay}

To assess soluble analytes secreted by MSC cultures at different passages, two LegendPLEX mouse panels (Th1/Th2 T Helper Cytokine Panel Version 2 and Mouse HSC Myeloid Panel) were used (BioLegend), according to the manufacturer's instructions. Briefly, the analytes were measured using bead-based sandwich immunoassays, which captured each soluble analyte between two antibodies. The analytes were bound by specific capture bead populations within a mixture of bead populations, which are differing in size and level of APC fluorescence, and each had specific antibody for a particular analyte on the surface. The concentration of each particular analyte was determined based on a known standard curve using the LEGENDplex ${ }^{\mathrm{TM}}$ data analysis software. The following panel of soluble analytes were measured in the supernatant of cells at various passages: IL-5, IL34, GM-CSF, M-CSF, CXCL12, TGF- $\beta 1$, SCF, IFN $\gamma$, IL-2, IL-4, IL-6, IL-10, IL-13, TNF $\alpha$.

\section{ELISA}

Concentrations of IL-1ra, CCL-6, HGF, Fractalkine, and Tissue Factor were determined from conditioned medium, using mouse ELISA duo set kits (R\&D Systems), following the manufacturer's protocols. Ang-2 and PGE2 were determined with a Mouse/Rat Angiopoietin-2 Quantikine ELISA Kit and Prostaglandin E2 Parameter Assay Kit, respectively (both from R\&D Systems), following the manufacturer's protocols.

\section{NO Determination}

The ability of the cells to produce NO was assessed by measuring the concentration of nitrite in the culture medium using Griess reagent, according to the manufacturer's instructions. Briefly, $100 \mu \mathrm{l}$ conditioned medium was incubated with $50 \mu \mathrm{l} 1 \%$ sulfanilamide and $50 \mu \mathrm{l} 0.3 \% \mathrm{~N}$-1-naphthylethylenediamine dihydrochloride (in $2.5 \% \mathrm{H}_{2} \mathrm{SO}_{4}$ ) for 30 minutes in the dark, to produce a colored azo product. The azo dye product was then spectrophotometrically quantitated based on its absorbance at $548 \mathrm{~nm}$, using a freshly prepared sodium nitrite standard curve.

\section{xCELLigence Analysis of Macrophage Activation}

The effect of MSC on macrophage activation was evaluated with xCELLigence system (Roche Applied Science), using murine macrophage cell line Raw 264.7 and LPS (10 ng/ml) for cell activation. xCELLigence system monitors cellular events in real time by measuring electrical impedance in E-plates, as previously described (9). Cell activation is displayed by increasing cell index in cells treated with LPS. Briefly, $4 \times 10^{4}$ cells were seeded onto each E-plate well in $200 \mu \mathrm{l}$ DMEM in the presence of LPS and $10 \%$ MSC-conditioned medium (CM) which was 10 times concentrated prior to analysis. Concentrated MSC-CM was obtained by ultrafiltration using centrifugal filter units with $3-\mathrm{kDa}$ cut-off (Millipore) and stored in aliquots at $-20^{\circ} \mathrm{C}$ until use. Controls of cells incubated with growth medium (negative control) and LPScontaining medium (positive controls) were also included.

\section{Xenotransplantation of Tumor Cells}

Mice were used in accordance to national and EU regulations for animal experimentation (Directive 2010/63/EU of the European Parliament) and all the procedures were approved by the Ethical Committee of ICBP. Mice were subcutaneously injected into the interscapular region with $50 \mu \mathrm{l}$ of cell suspension composed of $2 \times 10^{6}$ U87MG-luc2 cells, alone or mixed with $10^{6}$ MSC. Tumor development was monitored by in vivo imaging system, as described (35). Briefly, mice were intraperitoneally injected with luciferin (150 mg/Kg body weight) and 15 minutes later, they were imaged in dorsal position with IVIS Spectrum system (Perkin Elmer). The following settings were used: field of view 6.6; binning factor 4; F-stop 2; exposure 15 seconds. Surface images were then analyzed using Living Image 4.3.1 software (PerkinElmer, Norway) and quantification of bioluminescence was performed by manually defining regions of interest and reported as photons/ second/square centimeter/steradian. Six mice were sacrificed at 5 days after cell injection and cellular pellet was harvested for RNA isolation and Real-time RT-PCR analysis.

\section{Real-Time RT-PCR Analysis}

Total RNA (1 ug) was revers-transcribed into cDNA using HighCapacity RNA-to-cDNA Kit (Applied Biosystems). The qRTPCR was carried out using SYBR ${ }^{\mathrm{TM}}$ Select Master Mix (Applied Biosystems) with $400 \mathrm{nM}$ primer mix at a final reaction volume of $10 \mu \mathrm{L}$, on $\mathrm{ViiA}^{\mathrm{TM}} 7$ Real-Time PCR System. The cycling conditions were: $50^{\circ} \mathrm{C}$ for $2 \mathrm{~min}$ (UNG activation step), followed by $95^{\circ} \mathrm{C}$ for $2 \mathrm{~min}$ (enzyme activation step), and 40 cycles of amplification $\left(95^{\circ} \mathrm{C}\right.$ for $1 \mathrm{sec}$ and $60^{\circ} \mathrm{C}$ for $\left.30 \mathrm{sec}\right)$. Relative expression was calculated using the comparative CT method and S18 recognizing both human and mouse transcripts were used for normalization. 


\section{Statistical Analysis}

Statistical analysis was performed with GraphPad Prism 7 software. Results were expressed as mean \pm SD (in vitro studies) and mean \pm SEM (in vivo studies). Statistical comparisons of the secretome at different passages were performed via one-way ANOVA with Bonferroni corrections test applied for multiple comparisons. In vivo studies and inhibition studies were analyzed by two-way ANOVA with Tukey corrections for multiple groups. $\mathrm{p}<0.05$ was considered significant.

\section{RESULTS}

\section{Characterization of Contaminating Hematopoietic Cells in Bone Marrow- Derived MSC Culture}

Our strategy to purify mouse bone marrow-derived MSC in culture was based on serial passages through gentle trypsinization, by which MSC were detached and further propagated, while part of the hematopoietic cells remained attached to the substrate, being more resistant to trypsin. Figure 1A shows the decrease in the percentage of $\mathrm{CD} 45^{\text {pos }}$ cells in bone marrow-derived cell culture with each passage, until the culture became negative to CD45, after passage 6 . Within these first passages, a proliferation of hematopoietic cells was observed, as the percentage of $\mathrm{CD} 45^{\mathrm{pos}}$ cells increased from day 3 to day 5 after seeding (Supplemental Figure 1). We therefore named these cells bone marrow-derived proliferating hematopoietic cells (BM-PHC), a term that captures the origin and proliferative status of the contaminating CD $45^{\text {pos }}$ cells in the mouse MSC culture at low passages. It is worth mentioning that a large variability in the time course of the culture purification was noted, with certain batches of serum producing hematopoietic-free cultures early than others (data not shown).

Comparative characterization of BM-PHC and MSC was done at passage \#3 (at which BM-PHC represented more than $80 \%$ of total viable cells) and passage \#8 (at which culture MSC was free of hematopoietic cells). The results showed that BM-PHC were smaller-sized, however they expressed the whole panel of markers that are usually used to characterize MSC, except the endoglin (CD105). Thus, both cell populations were positive for Sca-1, CD44, CD29, and CD73 and were CD90 ${ }^{\text {low }}$ (Figure 1B). Comparative analysis of multipotency showed that BM-PHC could not generate adipocytes and chondrocytes in vitro (data not shown), as MSC did when cultured under appropriate conditions (28).

A
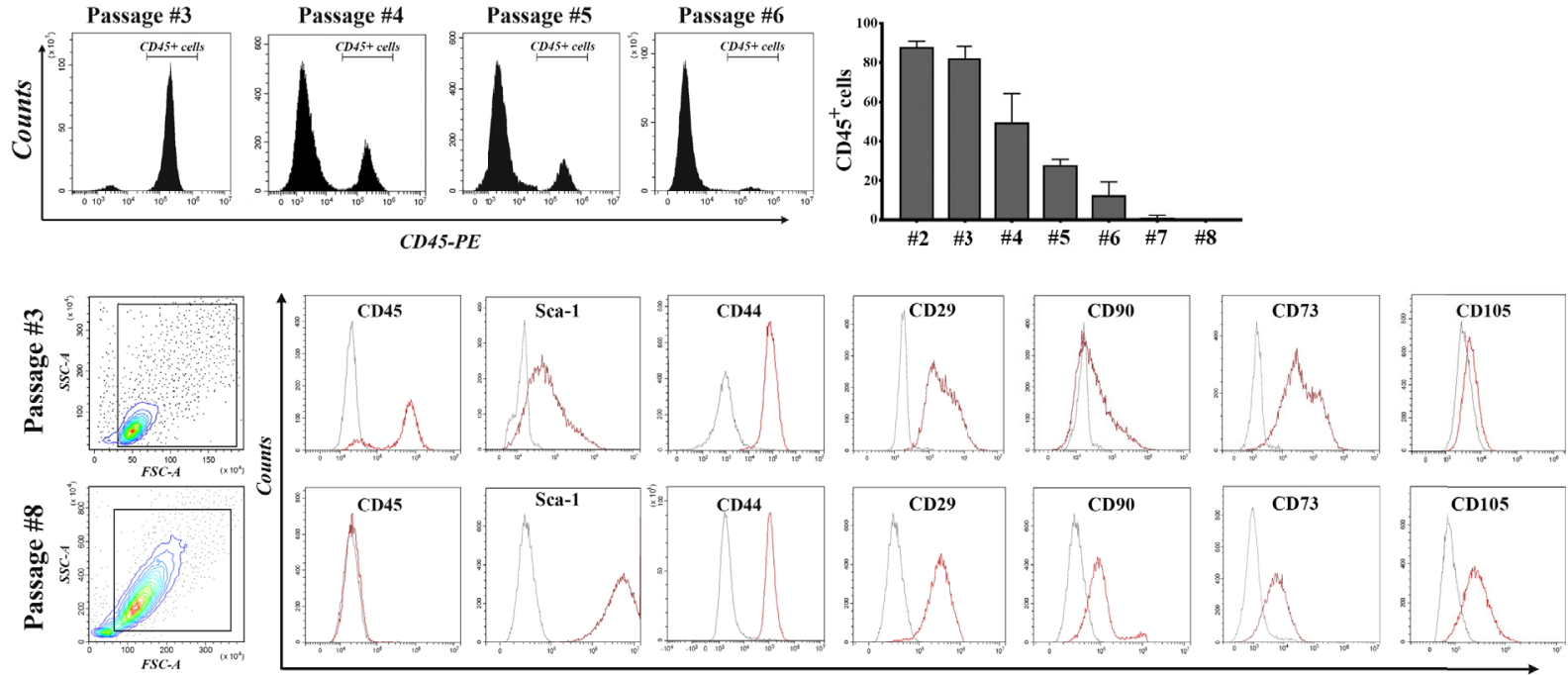

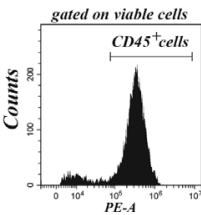

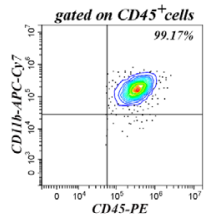
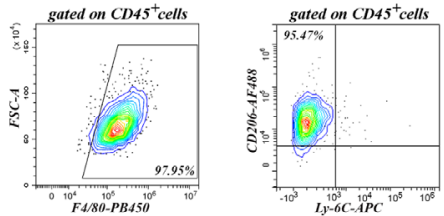

D
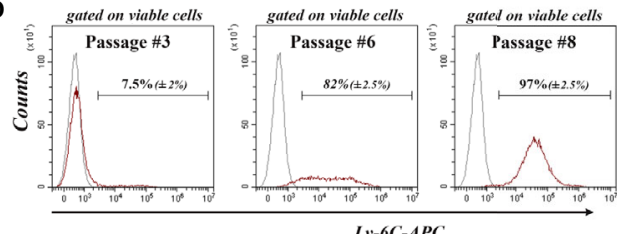

FIGURE 1 | Flow-cytometry characterization of cells emerged from mouse bone marrow aspirate during serial passages until total depletion of CD45 ${ }^{\text {pos }}$ cells. (A) The decrease in the percentage of CD45 ${ }^{\text {pos }}$ cells with each passage. Note that the culture becomes completely depleted of CD45 ${ }^{\text {pos }}$ cells after passage 6 . Data are mean +/- S.D of at least 6 experiments. (B) Comparative analysis of the expression of cell markers in culture at passages 3 and 8 . Note the presence of MSC markers (except CD105) on the cells at passage 3, when most of them are CD45 ${ }^{\text {pos }}$ cells. At passage 8 , the culture contained no CD45 ${ }^{\text {pos }}$ cells, and cells are CD105 pos (C) Characterization of hematopoietic cells at passage 3 . Note that all CD45 ${ }^{\text {pos }}$ cells (around $80 \%$ of total viable cells in culture) are CD11 pos/F4-80 $^{\text {pos/ }}$ CD206 ${ }^{\text {pos }} /$ Ly-6C ${ }^{\text {neg }}$, being therefore asserted as anti-inflammatory cells. At least 3 different batches were analyzed and the results were similar. (D) Expression of Ly$6 \mathrm{C}$ in cell culture at increasing passages. Note that all MSC express Ly-6C in culture. Data are mean +/- S.D of at least 3 experiments. 
Further characterization of BM-PHC showed a population of $\mathrm{CD} 11 \mathrm{~b}^{\text {pos }} / \mathrm{F} 4 / 80^{\text {pos }} / \mathrm{CD} 206^{\text {pos }} / \mathrm{Ly}-6 \mathrm{C}^{\text {neg }}$ cells, which pointed towards an anti-inflammatory macrophage phenotype (Figure 1C). Importantly, Ly-6C and Ly-6G were not expressed on BM-PHC however, Ly-6C was noticed on MSC. As the percentage of $\mathrm{CD} 45^{\text {pos }}$ cells decreased in culture, the percentage of $\mathrm{Ly}-6 \mathrm{C}^{\text {pos }}$ cells increased and all cells at passage \#8 were positive to Ly-6C (Figure 1D). Therefore, Ly-6C is being proposed as a genuine marker for $\mathrm{C} 57 \mathrm{Bl} / 6$-derived MSC.

\section{Comparative Analysis of the Immunomodulatory Properties of BM-PHC and MSC}

These small BM-PHC are the most abundant cells at passage \#3, yet the function of these cells is unknown. Consequently, we comparatively evaluated the immunomodulatory properties of BM-PHC (as whole population at passage \#3) and MSC at passages \#6 (in which the percentage of contaminating cells was very low), and \#10 (in which MSC had underwent several doublings in culture after total hematopoietic depletion), by coculturing them with syngeneic splenic $\mathrm{T}$ cells in activating conditions. In corroboration to previous reports (36), our results showed a dose-dependent inhibitory effect of MSC on T cell proliferation (Figure 2A and Supplemental Figure 2), with no difference between MSC at passages \#6 and \#10. However, passage \#3 was significantly more effective in suppressing $\mathrm{T}$ cell proliferation in comparison to passages \#6 and \#10, thus demonstrating a strong immunosuppressive effect of BMPHC (Figure 2A).

We next evaluated the effects of BM-PHC and MSC on resting $\mathrm{T}$ cells in culture. The results showed a dose-dependent protective effect of MSC (Figure 2B and Supplemental Figure 3) at both passages \#6 and \#10, and again, a much more protective effect of BM-PHC (Figure 2B).

We then attempted to establish whether secreted soluble factors were involved in the immunosuppression properties of these cells. First, the impact of MSC on T cell proliferation was assessed at passage \#6 in a transwell co-culture, without allowing direct cell contact. The results showed that, even in the absence of cell-to-cell contact, the immunosuppressive effect of MSC still remained significant (Figure 2C), thus emphasizing that the secretome produced by MSC was partially responsible for inhibition of $\mathrm{T}$ cell cycling. In addition, the secretome of either MSC or BM-PHC also had pro-survival effects on resting T cells in culture, albeit at lower extents than the cells (Figure 2D, in comparison to Figure 2B).

Together, these data demonstrated strong immunomodulatory properties of cells contaminating the MSC culture, which even surpassed the properties of MSC themselves, by promoting the viability of resting $\mathrm{T}$ cells and suppressing splenic $\mathrm{T}$ lymphocyte proliferation.

\section{Comparative Analysis of the Secretomes of MSC and BM-PHC}

The above data showed that the immunomodulatory effects of MSC and BM-PHC could be reproduced to a certain extent by the soluble factors secreted by these cells. To search for candidate molecules involved in the immunomodulatory properties of these cells, their CM was assessed by cytokine array. Around 22 proteins were identified at high levels (Supplemental Figure 4), with 6 of them having considerable differences in the secretion level between the two cell types. Specifically, Angiopoietin-2 (Ang-2), Hepatocyte Growth Factor (HGF), Fractalkine, Tissue Factor and Interleukin-1 receptor antagonist (IL-1ra) were secreted at higher levels by MSC than BM-PHC. On contrary, CCL6 (a mouse C-C motif chemokine), with chemoattractant properties for macrophages, $\mathrm{B}$ and $\mathrm{T}$ lymphocytes and eosinophils (37), was secreted at higher level by BM-PHC (Figure 3A).

The different secretion level of these molecules was further assessed by ELISA, using four different batches at different passages. The results confirmed the gradual decrease of CCL6 level with increasing passage (Figure 3B), thus suggesting that BM-PHC was the source of CCL6. Quantification of Ang-2 level in various batches at different passages showed batch-dependent secretion patterns, with some batches secreting high levels of Ang-2 at high passages (Supplemental Figure 4), and other batches secreting very low levels at all passages (Supplemental Figure 5). Quantification of IL-1ra revealed a high, yet wideranging secretion level between passages, with no validated increased level in MSC as compared to BM-PHC (Supplemental Table 1). On contrary, the increase in the secreted levels of Fractalkine and HGF with increasing passage was validated by ELISA, and very low levels of molecules were detected in BM-PHC (Figure 3C and Supplemental Figure 5). Similarly, Tissue Factor increased in MSC with passages (Supplemental Figure 5); however, it is worth mentioning that the levels of Tissue Factor were very low, ranging from 5 - 50 pg/ $\mathrm{ml}$. This data is important for intravascular therapeutic delivery of MSC, as Tissue Factor is the major determinant of cell product hemocompatibility (38). On the other hand, both cell types secreted high levels of Prostaglandin E2 (PGE2) at all passages, which were 3 orders of magnitude above the Tissue Factor level, with a median of around $4 \mathrm{ng} / \mathrm{ml}$ (data not shown). PGE2 was reported to be markedly increased in the inflammatory settings and has roles in inhibition of cytotoxic $\mathrm{T}$ cell development, division and function (39).

To get deeper insights into the composition of the secretome, two bead-based multiplex assay panels were used to quantify several mouse cytokines specifically associated to $\mathrm{T}$ helper or myeloid stem cells. The results showed no or minimal secretion levels of IL-2, -4, -5, -6, -10,-13,-34, as well as of Interferon $\gamma$ (IFN- $\gamma$ ), Tumor Necrosis Factor $\alpha$ (TNF- $\alpha$ ), Tissue Growth Factor $\beta 1$ (TGF- $\beta 1$ ), Granulocyte/Macrophage Colony Stimulating Factor (GM-CSF) and Stem Cell Factor (SCF), which thus confirmed the data obtained by cytokine array (Supplemental Table 1). Instead, very high levels of Macrophage Colony Stimulating Factor (M-CSF) were found in the CM of both cell types, with significantly higher levels secreted by MSC as compared to BM-PHC (Figure 3D). Likewise, CXCL12/SDF-1, a chemokine involved in stem cell homing and $\mathrm{T}$ cell chemoattraction had been found in higher levels in MSC than 
A
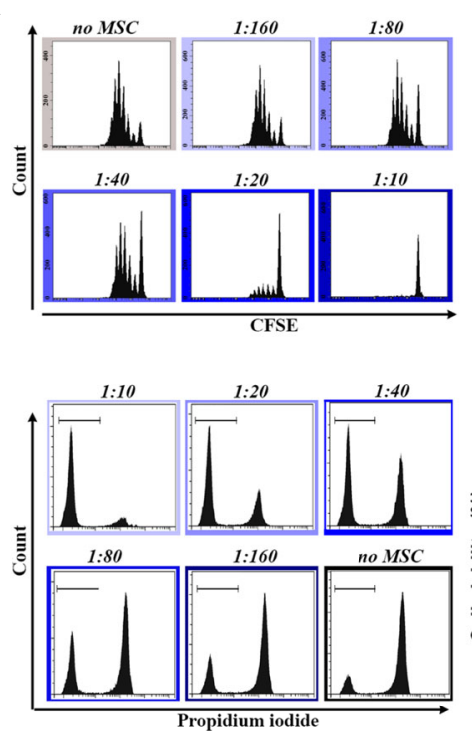

C
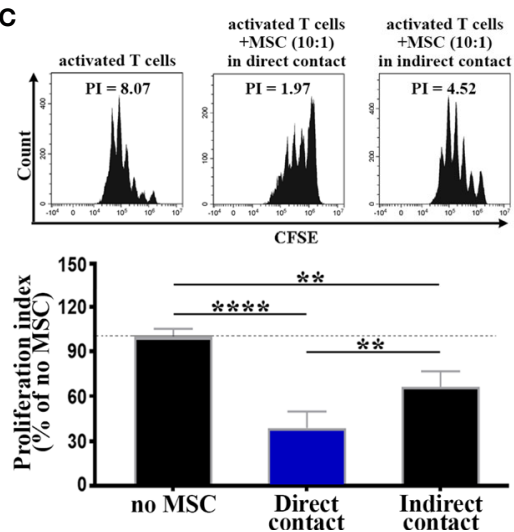
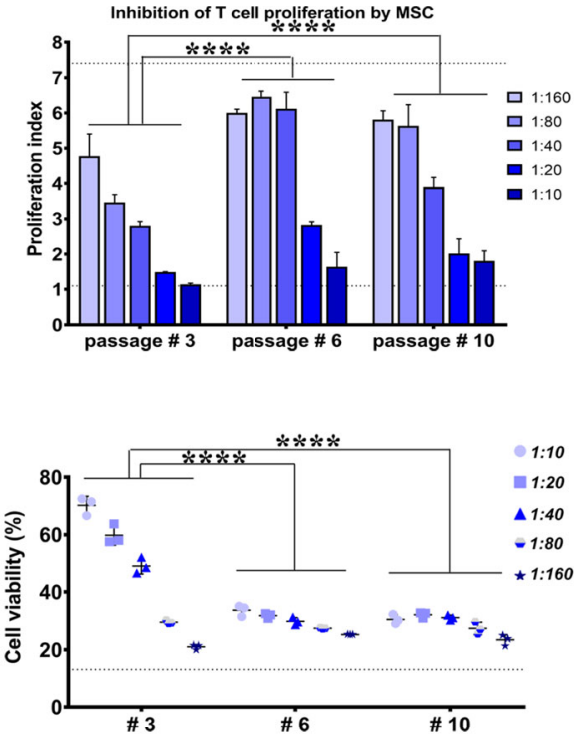

D
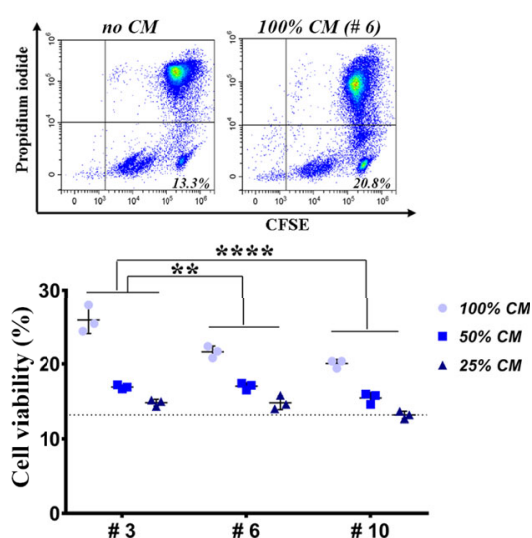

FIGURE 2 | Comparative analysis of the immunomodulatory properties of cells within culture at low, intermediate and high passages. (A) The immunosuppressive effect of cells on splenic T cell proliferation in vitro. T cells were cultured in the presence of activating beads (1:1 ratio) and increasing numbers of irradiated cells, so that to span the interval of MSC: T cell ratio between 1:160 and 1:10 (constant number of T cells). Shown data represent mean $+/-$ SD of one representative experiment performed in triplicates. At least three experiments were performed with similar results. (B) The pro-survival effect of cells on the viability of resting $T$ cells in vitro. T cells were cultured in resting conditions in the presence of increasing numbers of irradiated cells. Shown data represent mean $+/-\mathrm{SD}$ of one representative experiment performed in triplicates. At least three experiments were performed with similar conclusions. (C) The suppressive effect of MSC (passage \#6) on T cell proliferation in vitro, in the absence of cell-cell contact between MSC and T cells. (D) The pro-survival effect of the conditioned medium (CM) produced by cells on resting $T$ cells in vitro. Shown data represent mean $+/-$ SD of one representative experiment performed in triplicates. At least six experiments were performed with same conclusion. ${ }^{* \star} \mathrm{p}<0.01$, ${ }^{\star \star \star *} \mathrm{p}<0.001$.

in BM-PHC. Both M-CSF and CXCL12 have been previously reported as being secreted by MSC and involved in the control of survival and differentiation of bone marrow progenitor cells (40). A summary of all molecules identified in MSC secretome is illustrated in Supplemental Table 1.

\section{Candidate Molecules for the Immunosuppressive Effects of MSC and BM-PHC}

The above data showed that BM-PHC secreted high levels of CCL6, whereas MSC secreted high levels of HGF, Fractalkine,
M-CSF and CXCL12. However, both cells types secreted high levels of PGE2, previously reported to modulate the immunity (41) and the immunosuppressive properties of MSC (42). We therefore hypothesized that the immunosuppressive effect of both cell types is primarily mediated by PGE2, and to lesser extents by HGF and CCL6, which were differentially secreted by the two cell types. To test this hypothesis, proliferation studies of activated $\mathrm{T}$ cells in co-culture with MSC or BM-PHC in the presence of specific inhibitors of PGE2, HGF or CCL6 were done. BM-PHC were used for studying the effect of CCL6 and MSC for studying the effects of PGE2 and HGF. Our data showed that 

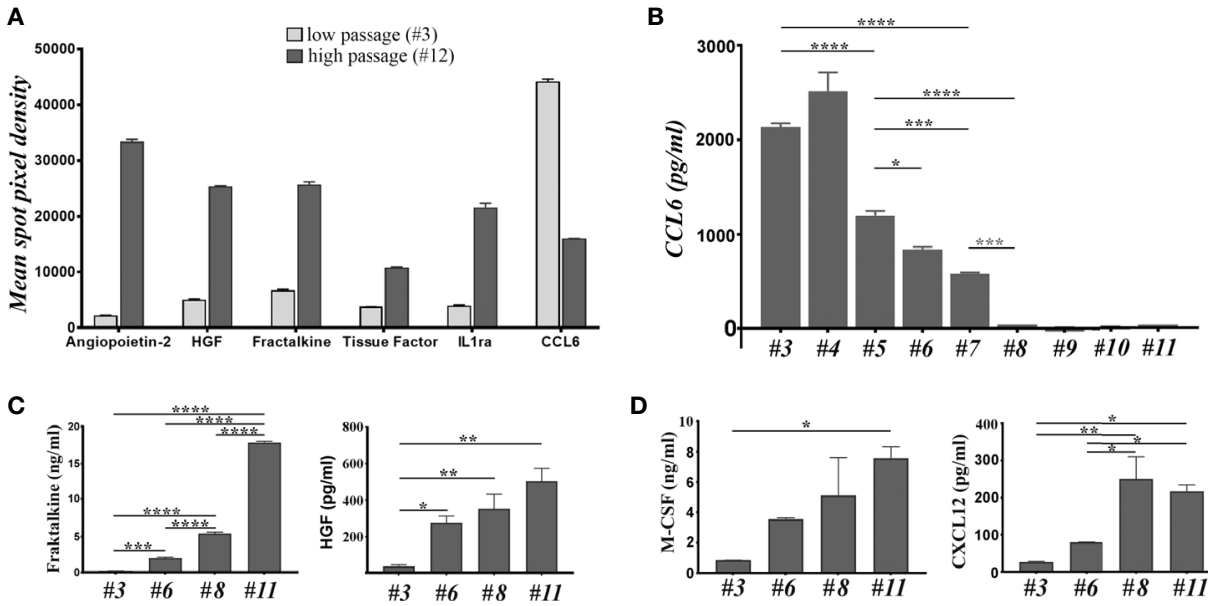

D

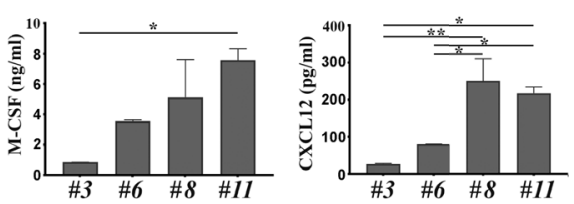

FIGURE 3 | The analysis of soluble factors secreted by cells at low and high passages. (A) The relative expression level of 6 cytokines identified by cytokine array in the secretome of cells at 3 versus \# 12. The depicted cytokines were selected from the 111 soluble proteins detected by cytokine array based on two considerations: a high level of expression and high differences between the two passages. (B) ELISA quantification of CCL-6 in the secretome of cells at increasing passages. Note the high level of CCL-6 at low passages and its loss after passage 7. The data represent the results of one representative experiment from 5 experiments with different batches and similar conclusions. (C) ELISA quantification of Fractalkine and HGF in the secretome of cells at different passages. The data represent the mean+/- S.D. @ of at least 3 experiments performed in duplicates. Note that Fractalkine is secreted by cell culture at all passages, while HGF is completely absent from the culture at low passage. (D) The LegendPlex quantification of M-CSF and CXCL12 in the secretome of cell culture at different passages. Data illustrates one experiment performed in duplicates. Two independent experiments with different batches were analyzed and the results were similar. ${ }^{\star} \mathrm{p}<0.05$, ${ }^{* \star} p<0.01,{ }^{* \star *} p<0.005,{ }^{* \star *} p<0.001$.

NS398, a specific COX-2 inhibitor, partially reversed the suppressive effect of MSC and increased the proliferation index of $\mathrm{T}$ cells at doses ranging from 1 to $10 \mu \mathrm{M}$ (Figure 4A). This effect was apparent only at 1:160, and not 1:10, cell ratio (MSC: T cell), which thus suggested a partial contribution of PGE2 on the inhibitory effects of MSC on T cell proliferation in vitro.

Interestingly, inhibition of CCL6 by using a specific neutralizing antibody significantly attenuated the inhibitory effect of BM-PHC at both $1: 160$ and $1: 10$ cell ratios (Figure 4B). This data showed a major suppressive role of CCL6 on $\mathrm{T}$ cell proliferation in vitro, which has not been previously reported and might explain the enhanced immunomodulatory properties of BM-PHC over MSC. However, the specific blocking of CCR1 (reported as the putative receptor of CCL6) (37), using BX471 small molecule, totally suppressed $\mathrm{T}$ cell proliferation (Supplemental Figure 6A), which probably reflected the involvement of other CC chemokines, such as CCL3, or CCL5 (which are synthetized by $\mathrm{T}$ cells and also signalize through CCR1 $(43,44)$, in cell survival and proliferation.

Similarly, inhibition of HGF signaling using SGX523 (a specific c-Met inhibitor) negatively impacted the $\mathrm{T}$ cell proliferation in vitro (Supplemental Figure 6B), which pointed towards the important role of HGF in cell proliferation and survival. However, addition of recombinant HGF protein (50-100 ng/ml) on activated T cells did not produce inhibitory effects (data not shown), suggesting that HGF was not involved in the suppressive effect of MSC on T cell proliferation in culture.
Collectively, these data indicated that CCL6 secreted by BM$\mathrm{PHC}$, yet not by MSC, might explain the superior effects of BM$\mathrm{PHC}$ in inhibiting activated $\mathrm{T}$ cell proliferation in vitro, as compared to MSC. PGE2, which was secreted at high levels by both cell types, was found to be partially involved in the inhibitory effects on $\mathrm{T}$ cell proliferation, yet the degree of inhibition did not point towards PGE2 as the major inhibitory molecule. We therefore assumed that T-cell suppression might be also mediated by factors induced in the presence of activated $\mathrm{T}$ cells, by the cross-talk between the two cell populations.

As nitric oxide (NO) was previously reported to inhibit T-cell proliferation in vitro $(45,46)$, we investigated the effects of $\mathrm{L}$ NAME, a specific inhibitor of NO synthase. As shown in Figure 4C, $1 \mathrm{mM}$ L-NAME partially reversed the immunosuppressive effects of MSC and its effect was more pronounced in the presence of low numbers of MSC (at MSC: T cell ratio of 1:40 and above). This data suggested that $\mathrm{NO}$ was also an important suppressive factor of $\mathrm{T}$ cells in vitro. However, complete recovery was not achieved, implying that a synergistic immunosuppressive mechanism of MSC on T cell proliferation did exist.

\section{Putative Mechanisms by Which MSC Induce Suppression of T Cell Proliferation}

Since NO is known as a highly unstable molecule, we next investigated the context in which NO secretion occurred in cultured MSC. To this aim, supernatants from naïve MSC culture, as well as from the 3-day co-culture of MSC with T cells in activating or quiescent conditions, were used for nitrite determination by Griess reaction. The results showed that MSC 


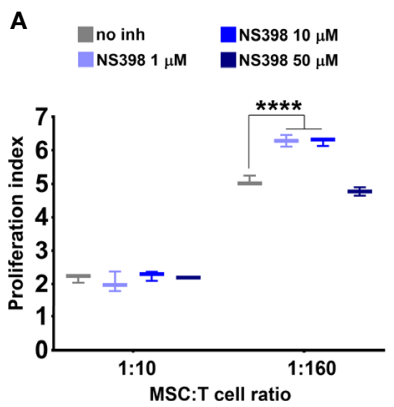

B no inh
aCCL-6 $5 \mu \mathrm{g} / \mathrm{ml} \quad$ aCCL-6 $10 \mu \mathrm{g} / \mathrm{ml}$
aCCL-6 $20 \mu \mathrm{g} / \mathrm{ml}$$\quad$ aCCL-6 $40 \mu \mathrm{g} / \mathrm{ml}$

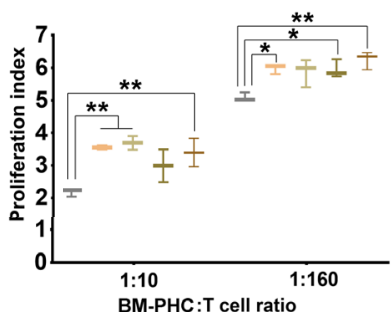

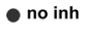

1 mM L-NAME

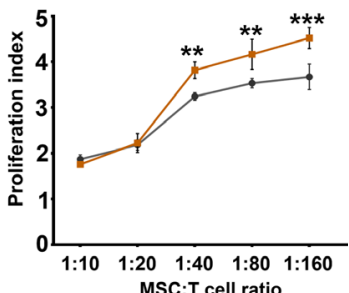

FIGURE 4 | The effects of cells on T cell proliferation in the presence of inhibitors. (A) Effect of different doses of NS398, a specific COX-2 inhibitor, on reversing the inhibitory effect of MSC. Note the capacity of NS398 at 1 and $10 \mu \mathrm{M}$ to partially reverse the MSC effect on T cell proliferation at the lowest MSC: T cell ratio. (B) Effect of different doses of CCL-6 neutralizing antibody on reversing the inhibitory effect of BM-PHC. Note the reversing effects of anti-CCL-6 at both BM-PHC: $T$ cell ratios. The graphics in a-b illustrate a representative experiment from at least four experiments performed with different batches, with the same conclusions. (C) Effect of L-NAME, a specific NO synthase inhibitor, on reversing the inhibitory effect of MSC. The graphic illustrates a representative experiment from three experiments preformed with different L-NAME doses: $100 \mathrm{nM}, 500 \mathrm{nM}$, and $1 \mathrm{mM}$. No dose-dependent effect of L-NAME was observed, yet the three doses produced the same reversing effects. ${ }^{*} \mathrm{p}<0.05,{ }^{\star \star} \mathrm{p}<0.01,{ }^{\star \star \star *} \mathrm{p}<0.005,{ }^{\star \star \star \star} \mathrm{p}<0.001$.

produced high levels of nitrite in the presence of activated T cells (Figure 5A). On contrary, neither naïve MSC, nor MSC in the presence of resting $\mathrm{T}$ cells did produce nitrite.

As MSC were previously reported to produce NO when activated by TNF $\alpha$ and IFN $\gamma$ (46) and both these molecules were identified in the secretome of activated $\mathrm{T}$ cells (47), we measured the nitrite level in the culture medium of naïve MSC in the presence of various doses of TNF $\alpha$ and IFN $\gamma$, alone or in combination. The results showed small levels of NO secreted by MSC in the presence of TNF $\alpha$, in a dose-dependent manner, and no NO secreted in the presence of IFN $\gamma$ alone. However, the concomitant presence of the two cytokines in MSC culture resulted in a massive NO secretion (Figure 5B). No significant difference was found in the NO levels produced by MSC and BM-PHC (Figure 5C). It is therefore likely that, similar to PGE2, NO production was a common mechanism by which the two cell types induced the suppression of T- cell proliferation in vitro.

Given the anti-inflammatory behavior of MSC in the presence of inflammatory cytokines, we investigated whether the expression of pro-inflammatory protein Ly-6C was changed in MSC in our experimental setting. Flow-cytometry analysis revealed that TNF $\alpha$ produced a dose-dependent decrease in the expression of Ly-6C in MSC culture (Figure 5D). On contrary, IFN $\gamma$ increased the Ly-6C expression in MSC culture, thus suggesting that the balance between the two cytokines dictates the overall expression of Ly-6C on MSC. We further determined Ly-6C expression in MSC in co-culture with activated T cells and found it increased, as compared to naïve MSC (Figure 5E). This data might be explained through increased level of INF $\gamma$ being secreted over TNF $\alpha$ in this experimental setting.

By summarizing, the factors by which MSC exerted the immunosuppressive effects on $\mathrm{T}$ cell proliferation in vitro appear to involve the constitutive secretion of PGE2 and the induced secretion of NO. Besides these two molecules, BM-PHC appear to exert the immunosuppressive effects on $\mathrm{T}$ cell proliferation in vitro also by CCL6.

\section{Capacity of BM-PHC and MSC to Inhibit Xenogeneic Tumor Formation in Immunocompetent Mice}

Having the strong immunosuppressive effects of BM-PHC and MSC on T cell proliferation in vitro, we attempted to evaluate whether these two cell types would induce tolerance to tumor development in a model of xenotransplantation of tumor cells in adult mice with intact immune system. To this aim, $2 \times 10^{6} \mathrm{U}-87$ MG-luc2 cells (human glioblastoma - derived cells that constitutively expresses Luciferase) were subcutaneously injected in C57Bl/6J mice, either alone, or mixed with $1 \times 10^{6}$ $\mathrm{BM}-\mathrm{PHC}$ or MSC. In vivo bioluminescence imaging demonstrated that, in the absence of cell therapy, the tumor rejection occurred between days 3 and 9 in all groups, with complete rejection occurring by day 11 (Figures 6A, B). Similar results with U-87 MG-luc2 cells injected into immunocompetent mice were previously reported (48). The group receiving tumor cells mixed with BM-PHC showed a transient increase in the luminescent signal within the first three days after transplant, followed by tumor rejection by day 9 , a pattern similar to control group. This data suggests no significant effects of BM-PHC on tumor development.

In contrast, co-injection of U-87 with MSC resulted in a significantly more rapid rejection of the xenograft, indicating a direct anti-tumoral effect of MSC (Figure 6A). As tumor growth was visibly affected from the first day after implantation (Figure 6B), a direct impact of MSC on the innate immune cells invading the tumor was assumed. In vitro investigation of the effect of MSC secretome on the activation of macrophages showed a significant anti-inflammatory effect of MSC, by slowing down the cell index, indicative of macrophage activation in the presence of LPS (Figure 6C). A similar anti-inflammatory effect of MSC was noted in vivo, in the model of tumor xenotransplantation described above, where quantitative RNA analysis of tumors removed at five days after injection revealed a tendency of decrease in the CD45 mRNA level in U87+ MSC 


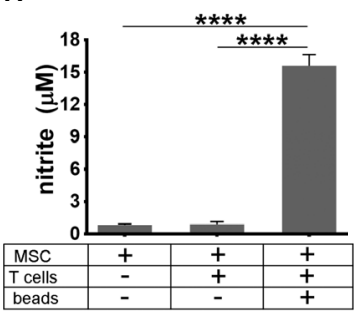

B

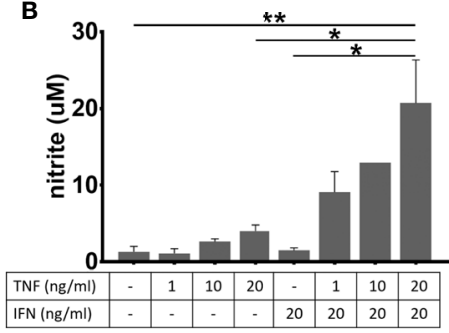

C

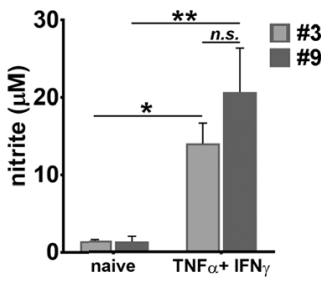

D

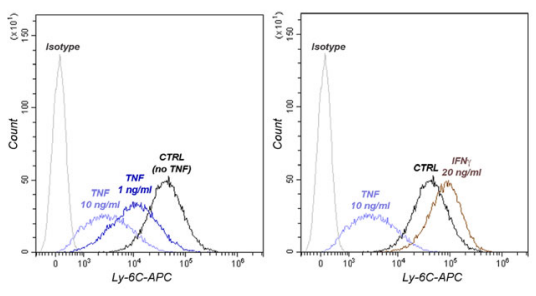

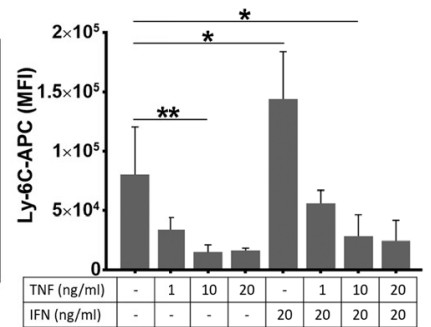

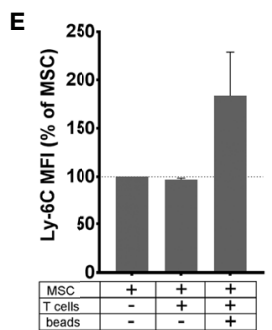

FIGURE 5 | The behavior of MSC in pro-inflammatory conditions. (A) The level of nitrite secreted by MSC in basal conditions, and in the co-culture with resting or proliferating T cells. The values represent mean+/- S.D. @ of two independent experiments performed in triplicates. (B) The levels of nitrite secreted by MSC after 48 hours of culture in the presence of TNF $\alpha$ and IFN $\gamma$. Note the synergic effect of the two cytokines on the secreted NO level. The values represent mean +/S.D of four experiments performed in duplicates with different MSC batches at passages 7-10. (C) The levels of nitrite secreted by cell culture at low and high passages. The values represent mean +/S.D of at least two experiments performed in duplicates. (D) The attenuation of Ly-6C expression on MSC after stimulation with TNF $\alpha$ in the presence or absence of IFN $\gamma$. Note that, while TNF $\alpha$ produced a dose-dependent decrease in the expression of Ly-6C in MSC culture, IFN $\gamma$ had an inverse effect, however in the presence of both cytokines, MSC decrease Ly-6C expression. The values represent the mean +/- S.D. from the three independent experiments. Representative histograms showing Ly-6C expression in MSC with and without cytokines are also given. (E) Ly-6C expression on MSC in basal conditions, and in the co-culture with resting or proliferating $T$ cells ( $n=2$ experiments). ${ }^{*} p<0.05,{ }^{* *} p<0.01,{ }^{* \star \star *} p<0.001$, n.s., not-significant.

group, as compared to U87 group (Figure 6D). The level of CD45 gene expression was positively correlated with the immunohistochemically-quantified cell marker in solid tumors, as previously documented (49). Still, RT-qPCR analysis identified increased transcription of several pro-inflammatory genes e.g., IL-1 $\beta$, IFN $\gamma$, COX-2, IL-12A (Figure 6D). A possible explanation for these results is that although MSC retained the anti-inflammatory properties in vivo, by reducing the number of hematopoietic cells infiltrated the transplant area, they underwent activation in the presence of tumor cells and consequently become polarized towards the inhibitory functionality for tumor development. However, due to the low number of animals used in this study, the statistical significance of the data was not reached. Therefore, additional studies are warranted to confirm this mechanism by which MSC act to inhibit tumor initiation in vivo.

Together, these data show that mouse bone marrow aspirate generates in culture two populations of proliferating cells with immunomodulatory properties, MSC and BM-PHC, which are valuable for therapeutic purposes. While both cell types inhibit the proliferation of activated $\mathrm{T}$ cells and promote the survival of resting $\mathrm{T}$ cells in vitro, the in vivo effects are divergent: MSC exert an anti-tumor effect, whereas BM-PHC may induce transplantation tolerance. Therefore, these two cell populations should be considered for cell therapy depending on the context.

\section{DISCUSSION}

The major findings of this study are summarized as follows: (i) bone marrow-derived MSC express high levels of Ly-6C; (ii) BMPHC, the hematopoietic cells contaminating the MSC culture at initial passages, have strong immunomodulatory properties on $\mathrm{T}$ cells in vitro, which were partially mediated by CCL6; (iii) $\mathrm{PGE}_{2}$ and NO, secreted by both MSC and BM-PHC, are common mediators of the suppression of $\mathrm{T}$ cell proliferation in vitro; (iv) MSC, yet not BM-PHC, exert anti-tumoral effects in vivo.

Increasing data on the immunomodulatory effects of MSC have shown that the mechanisms of action were largely paracrinemediated (50). However, substantial batch-to-batch variation, as well as differences based on donor, tissue of origin, culture conditions and passage were observed (51). We showed here that MSC secrete constitutively high levels of IL-1ra, Fractalkine, PGE2, HGF. Among them, PGE2 was validated as being involved in the immunosuppressive effects of MSC on T cells in vitro. As IL-1ra and fractalkine were acknowledged as molecules with opposite roles in lymphocyte recruitment $(52,53)$, their concomitant production by MSC may not produce a major impact on the immunosuppressive function. On the other hand, HGF was proven not to affect $\mathrm{T}$ cell proliferation in vitro. Neither addition of recombinant HGF, nor inhibition of HGF receptor in our co-culture system did reverse the immunosuppressive effects of MSC. This may not be surprising, 
A

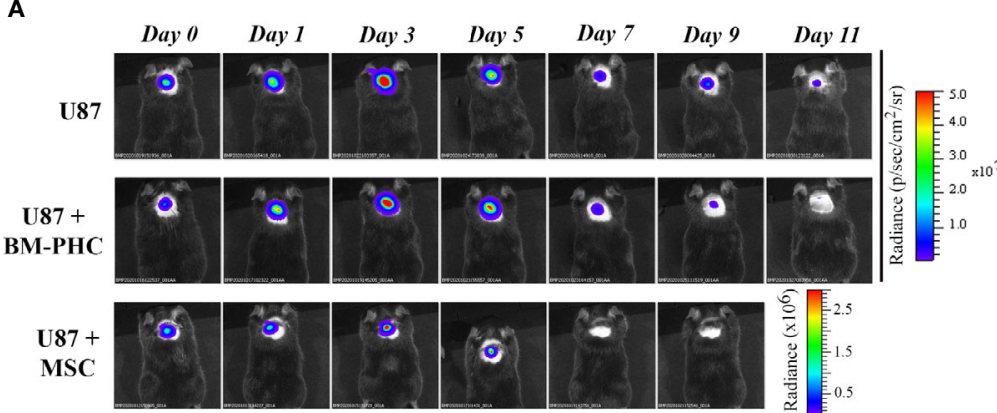

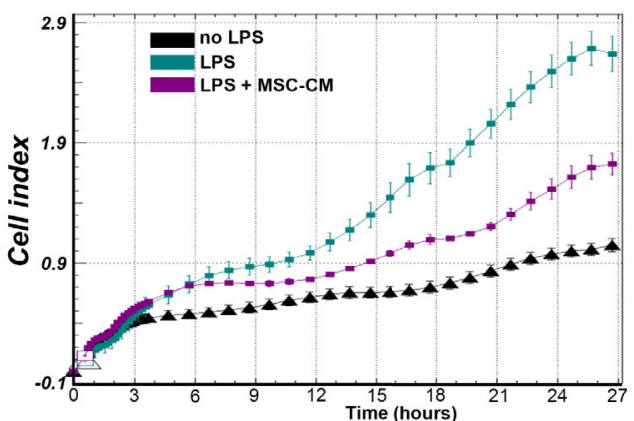

B

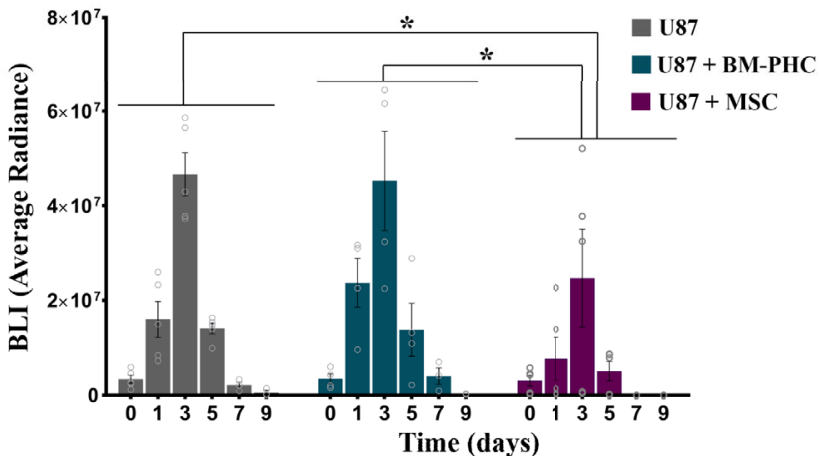

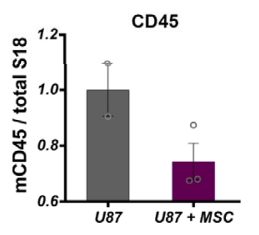

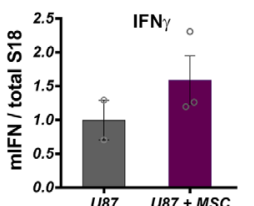

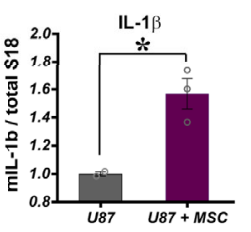

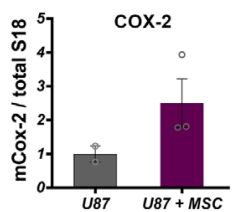

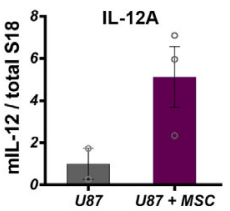

FIGURE 6 | The effects of BM-PHC and MSC on tumor development in immunocompetent mice. (A) A representative bioluminescent image of C57BI/6 mice subcutaneously transplanted with U87 cells alone (U87) or in the presence of BM-PHC or MSC is given above for each time point analyzed. (B) The diagram illustrates the bioluminescence signal of the tumor cells in all three groups, determined as average radiance. Values represent means+/-SEM of $n=4-5$ animals/group. (C) Dynamic assessment (original recording) of the effect of MSC secretome on macrophage activation in the presence of LPS. The recording represents mean values obtained from triplicates of one representative experiment from 2 experiments. (D) Quantification by real time RT-PCR ( $n=2-3$ per group) of the relative expression of genes associated with inflammation in cellular aggregates of tumor cells extracted after 5 days from implantation. ${ }^{*} p<0.05$.

as HGF mostly exerts its role on dendritic cells (54-56). Still, HGF has many other reported functions, such as induction of angiogenesis, promotion of cell proliferation and migration, and inhibition of apoptosis (57), which are accomplished through its receptor, c-Met. T cells were showed to express c-Met, which was reportedly involved in immune system activation against cancer cells overexpressing HGF (54). Our inhibitory studies showed that inhibition of $\mathrm{c}$-Met by SGX523 negatively affected T lymphocytes, thus emphasizing that HGF-c-Met signaling was crucial for normal cellular processes both in MSC and T cells.

Another mechanism of MSC-mediated immunosuppression involves NO secretion $(45,46,58)$. Our study showed that coculture of MSC with activated T cells in the presence of L-NAME partially reversed the MSC inhibitory effect. It is important to emphasize that this effect was elicited by IFN $\gamma$ and TNF $\alpha$, which were actively secreted by activated T cells $(59,60)$, and in their absence MSC did not produced NO $(40,46)$. Indeed, our in vitro studies confirmed that only MSC stimulated with both IFN $\gamma$ and TNF $\alpha$ produced high levels of nitrite in the culture medium.

In addition to the contribution of PGE2 and NO in MSCmediated immunosuppression of $\mathrm{T}$ cell proliferation, we showed here a decline in Ly-6C expression on MSC in the presence of TNF $\alpha$ and an increase in the presence of IFN $\gamma$, which suggested that the anti- or pro-inflammatory behavior of MSC was decided by the balance between these two cytokines in various settings (19). The presence of Ly-6C on MSC has not been acknowledged before. It would be interesting to find out if this expression is a particularity of these cells (C57Bl/6-derived MSC) or is a more generalized characteristic of mouse MSC.

We also report here that BM-PHC reveal similarities with antiinflammatory macrophages and share many characteristics with MSC, in terms of surface markers and immunomodulatory properties in vitro. These $\mathrm{CD} 45^{\mathrm{pos}}$ cells with positive expression of F4/80 and negative expression of Ly-6C and Ly-6G are different from the cell subset termed myeloid-derived suppressor cells (MDSC), which are basically inflammatory cells, and have been defined based on the high expression levels of Ly-6C (monocytederived MDSC) and/or Ly-6G (polymorphonuclear-derived MDSC) and lack of F4/80 molecules (61-64). However, these cells share several biological properties with MDSC, such as myeloid origin, in vitro proliferation, and suppressive potential for T cell proliferation. Other similarities of BM-PHC with MDSC refer to the mechanisms they use to suppress immune functions, as previous reports indicated that MDSC used inducible NO synthase and arginase for suppressing immune functions (65). Besides, upregulation of COX-2 and PGE2 by MDSC had also been mentioned among the mechanisms of immunosuppression (39).

BM-PHC secreted high levels of CCL6, which was partially involved in the suppressive effect of these cells on $\mathrm{T}$ cell proliferation. As CCL6 was not secreted by MSC, this molecule 
might explain the superior immunosuppressive effects of BM-PHC over MSC. In harmony with our results, a previous study suggested a role of CCL6 in the antileukemic immune response and CCL6 down-regulation as a mechanism adopted by leukemic cells to evade the immune system (66). Furthermore, another study reported an apoptotic effect of CCL6 on several cell lines (67).

In conclusion, multiple cell populations with immunomodulatory properties can be obtained from bone marrow aspirate. They all may be valuable for therapeutic purposes, however the individual effect of each of them should be established in disease-relevant contexts.

A possible debating conclusion based on results reported in this paper is the antitumor effect of MSC in vivo. Extensive studies have been previously conducted and conflicting results have been reported with regards to the role of MSC in cancer therapy (68). On the one hand, there are studies boosting the conceptualization of MSC-based experimental cancer therapy by showing that MSC prevented tumor progression and metastasis though inhibiting angiogenesis or suppressing immune responses (69-73). On the other hand, several other studies reported the pro-tumorigenic properties of MSC (74-77). Similarly, although in a different context, MSC were demonstrated to delay the allograft rejection and generate a local immune privileged site (78).

Another debate that may also hinder the therapeutic potential of MSC is the significant safety concerns regarding the possible longterm tumor growth after MSC infusion, as previously reported in mice (79). Such in vivo spontaneous malignant transformation of mouse MSC have been previously documented particularly after long-term in vitro culture $(80,81)$, which sustained the hypothesis that cell characteristics are dynamics and change depending on intracellular and extracellular stimuli. In our experimental setting, MSC co-administrated with tumor cells generated a more rapid xenograft rejection in immunocompetent mice. While MSC apparently decreased the murine CD45 expression inside the tumor, the tumor microenvironment induced MSC polarization towards the inhibitory functionality, which resulted in rapid tumor annihilation. However, in this paper we have only focused on the fate of tumor cells, yet not followed the long-term effects of MSC transplant, therefore we cannot deliberate on malignant transformation of MSC in vivo. However, MSC remain unquestionably a promising therapy option for a variety of diseases, yet despite numerous in vitro and in vivo studies, there is much more that is still unknown and as such, more research and observations will be necessary to investigate the long-term effects of MSC therapies.

\section{REFERENCES}

1. De Miguel MP, Fuentes-Julian S, Blazquez-Martinez A, Pascual CY, Aller MA, Arias J, et al. Immunosuppressive Properties of Mesenchymal Stem Cells: Advances and Applications. Curr Mol Med (2012) 12(5):574-91. doi: $10.2174 / 156652412800619950$

2. Prockop DJ. Marrow Stromal Cells as Stem Cells for Nonhematopoietic Tissues. Science (1997) 276(5309):71-4. doi: 10.1126/science.276.5309.71

3. Dezawa M, Ishikawa H, Itokazu Y, Yoshihara T, Hoshino M, Takeda S, et al. Bone Marrow Stromal Cells Generate Muscle Cells and Repair Muscle Degeneration. Science (2005) 309(5732):314-7. doi: 10.1126/science.1110364

4. Sasaki M, Abe R, Fujita Y, Ando S, Inokuma D, Shimizu H. Mesenchymal Stem Cells are Recruited Into Wounded Skin and Contribute to Wound

\section{DATA AVAILABILITY STATEMENT}

The raw data supporting the conclusions of this article will be made available by the authors, without undue reservation.

\section{ETHICS STATEMENT}

The animal study was reviewed and approved by the Ethical Committee of ICBP.

\section{AUTHOR CONTRIBUTIONS}

C-IM, MP, CN, ER, SP, and AB performed experiments. C-IM, $\mathrm{MP}$, and $\mathrm{AB}$ analyzed and interpreted the data. $\mathrm{AB}$ designed the work and wrote the manuscript. All authors contributed to the article and approved the submitted version.

\section{FUNDING}

This work was supported by a project co-financed by the European Regional Development Fund through the Competitiveness Operational Program 2014-2020 (POC-A.1A.1.1.4-E-2015, ID: P 37 668, acronym DIABETER) and Romanian Ministry of Education (PN-III-P1-1.1-PD-20161903, contract no 133PD/2018 and PN-III-P4-ID-PCE-20201340-contract 122/2021).

\section{ACKNOWLEDGMENTS}

The authors would like to thank Dr. Nadir Askenasy and Dr. Maya Simionescu for their valuable advice on the data interpretation.

\section{SUPPLEMENTARY MATERIAL}

The Supplementary Material for this article can be found online at: https://www.frontiersin.org/articles/10.3389/fimmu.2021. 698070/full\#supplementary-material.

Repair by Transdifferentiation Into Multiple Skin Cell Type. J Immunol (2008) 180(4):2581-7. doi: 10.4049/jimmunol.180.4.2581

5. Wei Q, Frenette PS. Niches for Hematopoietic Stem Cells and Their Progeny. Immunity (2018) 48(4):632-48. doi: 10.1016/j.immuni.2018.03.024

6. Mendez-Ferrer S, Michurina TV, Ferraro F, Mazloom AR, Macarthur BD, Lira SA, et al. Mesenchymal and Haematopoietic Stem Cells Form a Unique Bone Marrow Niche. Nature (2010) 466(7308):829-34. doi: 10.1038/nature09262

7. Trounson A, McDonald C. Stem Cell Therapies in Clinical Trials: Progress and Challenges. Cell Stem Cell (2015) 17(1):11-22. doi: 10.1016/j.stem.2015.06.007

8. Zhang M, Mal N, Kiedrowski M, Chacko M, Askari AT, Popovic ZB, et al. SDF-1 Expression by Mesenchymal Stem Cells Results in Trophic Support of Cardiac Myocytes After Myocardial Infarction. FASEB J (2007) 21(12):3197207. doi: 10.1096/fj.06-6558com 
9. Burlacu A, Grigorescu G, Rosca AM, Preda MB, Simionescu M. Factors Secreted by Mesenchymal Stem Cells and Endothelial Progenitor Cells Have Complementary Effects on Angiogenesis In Vitro. Stem Cells Dev (2013) 22 (4):643-53. doi: 10.1089/scd.2012.0273

10. Shabbir A, Zisa D, Suzuki G, Lee T. Heart Failure Therapy Mediated by the Trophic Activities of Bone Marrow Mesenchymal Stem Cells: A Noninvasive Therapeutic Regimen. Am J Physiol Heart Circ Physiol (2009) 296(6):H188897. doi: 10.1152/ajpheart.00186.2009

11. Preda MB, Ronningen T, Burlacu A, Simionescu M, Moskaug JO, Valen G. Remote Transplantation of Mesenchymal Stem Cells Protects the Heart Against Ischemia-Reperfusion Injury. Stem Cells (2014) 32(8):2123-34. doi: 10.1002/stem.1687

12. Preda MB, Lupan AM, Neculachi CA, Leti LI, Fenyo IM, Popescu S, et al. Evidence of Mesenchymal Stromal Cell Adaptation to Local Microenvironment Following Subcutaneous Transplantation. J Cell Mol Med (2020) 24(18):10889-97. doi: $10.1111 /$ jcmm.15717

13. Lee TM, Harn HJ, Chiou TW, Chuang MH, Chen $\mathrm{CH}$, Chuang $\mathrm{CH}$, et al. Remote Transplantation of Human Adipose-Derived Stem Cells Induces Regression of Cardiac Hypertrophy by Regulating the Macrophage Polarization in Spontaneously Hypertensive Rats. Redox Biol (2019) 27:101170. doi: 10.1016/j.redox.2019.101170

14. Balaji S, Keswani SG, Crombleholme TM. The Role of Mesenchymal Stem Cells in the Regenerative Wound Healing Phenotype. Adv Wound Care (New Rochelle) (2012) 1(4):159-65. doi: 10.1089/wound.2012.0361

15. Harman RM, Marx C, Van de Walle GR. Translational Animal Models Provide Insight Into Mesenchymal Stromal Cell (MSC) Secretome Therapy. Front Cell Dev Biol (2021) 9:654885. doi: 10.3389/fcell.2021.654885

16. Preda MB, Neculachi CA, Fenyo IM, Vacaru AM, Publik MA, Simionescu M, et al. Short Lifespan of Syngeneic Transplanted MSC Is a Consequence of In Vivo Apoptosis and Immune Cell Recruitment in Mice. Cell Death Dis (2021) 12(6):566. doi: 10.1038/s41419-021-03839-w

17. Abdi R, Fiorina P, Adra CN, Atkinson M, Sayegh MH. Immunomodulation by Mesenchymal Stem Cells: A Potential Therapeutic Strategy for Type 1 Diabetes. Diabetes (2008) 57(7):1759-67. doi: 10.2337/db08-0180

18. Weiss ARR, Dahlke MH. Immunomodulation by Mesenchymal Stem Cells (MSCs): Mechanisms of Action of Living, Apoptotic, and Dead MSCs. Front Immunol (2019) 10:1191. doi: 10.3389/fimmu.2019.01191

19. Regmi S, Pathak S, Kim JO, Yong CS, Jeong JH. Mesenchymal Stem Cell Therapy for the Treatment of Inflammatory Diseases: Challenges, Opportunities, and Future Perspectives. Eur J Cell Biol (2019) 98(58):151041. doi: 10.1016/j.ejcb.2019.04.002

20. Galipeau J, Krampera M, Barrett J, Dazzi F, Deans RJ, DeBruijn J, et al. International Society for Cellular Therapy Perspective on Immune Functional Assays for Mesenchymal Stromal Cells as Potency Release Criterion for Advanced Phase Clinical Trials. Cytotherapy (2016) 18(2):151-9. doi: 10.1016/j.jcyt.2015.11.008

21. Roux C, Saviane G, Pini J, Belaid N, Dhib G, Voha C, et al. Immunosuppressive Mesenchymal Stromal Cells Derived From HumanInduced Pluripotent Stem Cells Induce Human Regulatory T Cells In Vitro and In Vivo. Front Immunol (2017) 8:1991. doi: 10.3389/fimmu.2017.01991

22. Shi Y, Wang Y, Li Q, Liu K, Hou J, Shao C, et al. Immunoregulatory Mechanisms of Mesenchymal Stem and Stromal Cells in Inflammatory Diseases. Nat Rev Nephrol (2018) 14(8):493-507. doi: 10.1038/s41581-018-0023-5

23. Liu J, Liu Q, Chen X. The Immunomodulatory Effects of Mesenchymal Stem Cells on Regulatory B Cells. Front Immunol (2020) 11:1843. doi: 10.3389/ fimmu.2020.01843

24. Stevens HY, Bowles AC, Yeago C, Roy K. Molecular Crosstalk Between Macrophages and Mesenchymal Stromal Cells. Front Cell Dev Biol (2020) 8:600160. doi: $10.3389 /$ fcell.2020.600160

25. Caplan H, Olson SD, Kumar A, George M, Prabhakara KS, Wenzel P, et al. Mesenchymal Stromal Cell Therapeutic Delivery: Translational Challenges to Clinical Application. Front Immunol (2019) 10:1645. doi: 10.3389/fimmu.2019.01645

26. Caroti CM, Ahn H, Salazar HF, Joseph G, Sankar SB, Willett NJ, et al. A Novel Technique for Accelerated Culture of Murine Mesenchymal Stem Cells That Allows for Sustained Multipotency. Sci Rep (2017) 7(1):13334. doi: 10.1038/ s41598-017-13477-y

27. Soleimani M, Nadri S. A Protocol for Isolation and Culture of Mesenchymal Stem Cells From Mouse Bone Marrow. Nat Protoc (2009) 4(1):102-6. doi: $10.1038 /$ nprot.2008.221
28. Rosca AM, Burlacu A. Effect of 5-Azacytidine: Evidence for Alteration of the Multipotent Ability of Mesenchymal Stem Cells. Stem Cells Dev (2011) 20 (7):1213-21. doi: 10.1089/scd.2010.0433

29. Tropel P, Noel D, Platet N, Legrand P, Benabid AL, Berger F. Isolation and Characterisation of Mesenchymal Stem Cells From Adult Mouse Bone Marrow. Exp Cell Res (2004) 295(2):395-406. doi: 10.1016/j.yexcr.2003.12.030

30. Hu Y, Lou B, Wu X, Wu R, Wang H, Gao L, et al. Comparative Study on In Vitro Culture of Mouse Bone Marrow Mesenchymal Stem Cells. Stem Cells Int (2018) 2018:6704583. doi: 10.1155/2018/6704583

31. Peister A, Mellad JA, Larson BL, Hall BM, Gibson LF, Prockop DJ. Adult Stem Cells From Bone Marrow (MSCs) Isolated From Different Strains of Inbred Mice Vary in Surface Epitopes, Rates of Proliferation, and Differentiation Potential. Blood (2004) 103(5):1662-8. doi: 10.1182/blood-2003-09-3070

32. Boregowda SV, Krishnappa V, Phinney DG. Isolation of Mouse Bone Marrow Mesenchymal Stem Cells. Methods Mol Biol (2016) 1416:205-23. doi: 10.1007/ 978-1-4939-3584-0_11

33. Hathcock KS. T Cell Enrichment by Nonadherence to Nylon. Curr Protoc Immunol (1999) 30(1):3.2.1-4. doi: 10.1002/0471142735.im0302s30

34. Marinescu CI, Preda MB, Burlacu A. A Procedure for In Vitro Evaluation of the Immunosuppressive Effect of Mouse Mesenchymal Stem Cells on Activated T Cell Proliferation. Stem Cell Res Ther (2021) 12(1):319. doi: 10.1186/s13287-021-02344-3

35. Odent Grigorescu G, Preda MB, Radu E, Rosca AM, Tutuianu R, Mitroi DN, et al. Combinatorial Approach for Improving the Outcome of Angiogenic Therapy in Ischemic Tissues. Biomaterials (2015) 60:72-81. doi: 10.1016/ j.biomaterials.2015.05.002

36. Bloom DD, Centanni JM, Bhatia N, Emler CA, Drier D, Leverson GE, et al. A Reproducible Immunopotency Assay to Measure Mesenchymal Stromal CellMediated T-Cell Suppression. Cytotherapy (2015) 17(2):140-51. doi: 10.1016/ j.jcyt.2014.10.002

37. Coelho AL, Schaller MA, Benjamim CF, Orlofsky AZ, Hogaboam CM, Kunkel SL. The Chemokine CCL6 Promotes Innate Immunity via Immune Cell Activation and Recruitment. J Immunol (2007) 179(8):5474-82. doi: 10.4049/ jimmunol.179.8.5474

38. Moll G, Ankrum JA, Kamhieh-Milz J, Bieback K, Ringden O, Volk HD, et al. Intravascular Mesenchymal Stromal/Stem Cell Therapy Product Diversification: Time for New Clinical Guidelines. Trends Mol Med (2019) 25(2):149-63. doi: 10.1016/j.molmed.2018.12.006

39. Rodriguez PC, Hernandez CP, Quiceno D, Dubinett SM, Zabaleta J, Ochoa JB, et al. Arginase I in Myeloid Suppressor Cells is Induced by COX-2 in Lung Carcinoma. J Exp Med (2005) 202(7):931-9. doi: 10.1084/jem.20050715

40. Takizawa N, Okubo N, Kamo M, Chosa N, Mikami T, Suzuki K, et al. Bone Marrow-Derived Mesenchymal Stem Cells Propagate Immunosuppressive/ Anti-Inflammatory Macrophages in Cell-to-Cell Contact-Independent and -Dependent Manners Under Hypoxic Culture. Exp Cell Res (2017) 358 (2):411-20. doi: 10.1016/j.yexcr.2017.07.014

41. Harris SG, Padilla J, Koumas L, Ray D, Phipps RP. Prostaglandins as Modulators of Immunity. Trends Immunol (2002) 23(3):144-50. doi: 10.1016/S1471-4906(01)02154-8

42. Aggarwal S, Pittenger MF. Human Mesenchymal Stem Cells Modulate Allogeneic Immune Cell Responses. Blood (2005) 105(4):1815-22. doi: 10.1182/blood-2004-04-1559

43. Cocchi F, DeVico AL, Garzino-Demo A, Arya SK, Gallo RC, Lusso P Identification of RANTES, MIP-1 Alpha, and MIP-1 Beta as the Major HIV-Suppressive Factors Produced by CD8+ T Cells. Science (1995) 270 (5243):1811-5. doi: 10.1126/science.270.5243.1811

44. Galeano Nino JL, Pageon SV, Tay SS, Colakoglu F, Kempe D, Hywood J, et al. Cytotoxic T Cells Swarm by Homotypic Chemokine Signalling. Elife (2020) 9: e56554-93. doi: 10.7554/eLife.56554

45. Sato K, Ozaki K, Oh I, Meguro A, Hatanaka K, Nagai T, et al. Nitric Oxide Plays a Critical Role in Suppression of T-Cell Proliferation by Mesenchymal Stem Cells. Blood (2007) 109(1):228-34. doi: 10.1182/blood-2006-02-002246

46. Ren G, Zhang L, Zhao X, Xu G, Zhang Y, Roberts AI, et al. Mesenchymal Stem Cell-Mediated Immunosuppression Occurs via Concerted Action of Chemokines and Nitric Oxide. Cell Stem Cell (2008) 2(2):141-50. doi: 10.1016/j.stem.2007.11.014

47. Raphael I, Nalawade S, Eagar TN, Forsthuber TG. T Cell Subsets and Their Signature Cytokines in Autoimmune and Inflammatory Diseases. Cytokine (2015) 74(1):5-17. doi: 10.1016/j.cyto.2014.09.011 
48. Semenkow S, Li S, Kahlert UD, Raabe EH, Xu J, Arnold A, et al. An Immunocompetent Mouse Model of Human Glioblastoma. Oncotarget (2017) 8(37):61072-82. doi: 10.18632/oncotarget.17851

49. Kwak M, Erdag G, Slingluff CLJr. Gene Expression Analysis in Formalin Fixed Paraffin Embedded Melanomas Is Associated With Density of Corresponding Immune Cells in Those Tissues. Sci Rep (2020) 10(1):18336. doi: 10.1038/ s41598-020-74996-9

50. Viswanathan S, Shi Y, Galipeau J, Krampera M, Leblanc K, Martin I, et al. Mesenchymal Stem Versus Stromal Cells: International Society for Cell \& Gene Therapy (ISCT(R)) Mesenchymal Stromal Cell Committee Position Statement on Nomenclature. Cytotherapy (2019) 21(10):1019-24. doi: 10.1016/j.jcyt.2019.08.002

51. Yin JQ, Zhu J, Ankrum JA. Manufacturing of Primed Mesenchymal Stromal Cells for Therapy. Nat BioMed Eng (2019) 3(2):90-104. doi: 10.1038/s41551018-0325-8

52. Ortiz LA, Dutreil M, Fattman C, Pandey AC, Torres G, Go K, et al. Interleukin 1 Receptor Antagonist Mediates the Antiinflammatory and Antifibrotic Effect of Mesenchymal Stem Cells During Lung Injury. Proc Natl Acad Sci USA (2007) 104(26):11002-7. doi: 10.1073/pnas.0704421104

53. Jones BA, Beamer M, Ahmed S. Fractalkine/CX3CL1: A Potential New Target for Inflammatory Diseases. Mol Interv (2010) 10(5):263-70. doi: 10.1124/mi.10.5.3

54. Hubel J, Hieronymus T. HGF/Met-Signaling Contributes to Immune Regulation by Modulating Tolerogenic and Motogenic Properties of Dendritic Cells. Biomedicines (2015) 3(1):138-48. doi: 10.3390/biomedicines3010138

55. Ilangumaran S, Villalobos-Hernandez A, Bobbala D, Ramanathan S. The Hepatocyte Growth Factor (HGF)-MET Receptor Tyrosine Kinase Signaling Pathway: Diverse Roles in Modulating Immune Cell Functions. Cytokine (2016) 82:125-39. doi: 10.1016/j.cyto.2015.12.013

56. Sagi Z, Hieronymus T. The Impact of the Epithelial-Mesenchymal Transition Regulator Hepatocyte Growth Factor Receptor/Met on Skin Immunity by Modulating Langerhans Cell Migration. Front Immunol (2018) 9:517. doi: 10.3389/fimmu.2018.00517

57. Papaccio F, Della Corte CM, Viscardi G, Di Liello R, Esposito G, Sparano F, et al. HGF/MET and the Immune System: Relevance for Cancer Immunotherapy. Int J Mol Sci (2018) 19(11):3595-607. doi: 10.3390/ijms19113595

58. Chen X, Gan Y, Li W, Su J, Zhang Y, Huang Y, et al. The Interaction Between Mesenchymal Stem Cells and Steroids During Inflammation. Cell Death Dis (2014) 5:e1009. doi: 10.1038/cddis.2013.537

59. Bushkin Y, Radford F, Pine R, Lardizabal A, Mangura BT, Gennaro ML, et al. Profiling T Cell Activation Using Single-Molecule Fluorescence In Situ Hybridization and Flow Cytometry. J Immunol (2015) 194(2):836-41. doi: 10.4049/jimmunol.1401515

60. Nakiboneka R, Mugaba S, Auma BO, Kintu C, Lindan C, Nanteza MB, et al. Interferon Gamma (IFN-Gamma) Negative CD4+ and CD8+ T-Cells can Produce Immune Mediators in Response to Viral Antigens. Vaccine (2019) 37 (1):113-22. doi: 10.1016/j.vaccine.2018.11.024

61. Bronte V, Brandau S, Chen SH, Colombo MP, Frey AB, Greten TF, et al. Recommendations for Myeloid-Derived Suppressor Cell Nomenclature and Characterization Standards. Nat Commun (2016) 7:12150. doi: 10.1038/ncomms12150

62. Lee HJ, Ko JH, Kim HJ, Jeong HJ, Oh JY. Mesenchymal Stromal Cells Induce Distinct Myeloid-Derived Suppressor Cells in Inflammation. JCI Insight (2020) 5(12):e136059-74. doi: 10.1172/jci.insight.136059

63. Schmid M, Zimara N, Wege AK, Ritter U. Myeloid-Derived Suppressor Cell Functionality and Interaction With Leishmania Major Parasites Differ in C57BL/6 and BALB/c Mice. Eur J Immunol (2014) 44(11):3295-306. doi: 10.1002/eji.201344335

64. Fang Z, Wen C, Chen X, Yin R, Zhang C, Wang X, et al. Myeloid-Derived Suppressor Cell and Macrophage Exert Distinct Angiogenic and Immunosuppressive Effects in Breast Cancer. Oncotarget (2017) 8(33):5417386. doi: 10.18632 /oncotarget. 17013

65. Youn JI, Gabrilovich DI. The Biology of Myeloid-Derived Suppressor Cells: The Blessing and the Curse of Morphological and Functional Heterogeneity. Eur J Immunol (2010) 40(11):2969-75. doi: 10.1002/eji.201040895

66. Nardi V, Naveiras O, Azam M, Daley GQ. ICSBP-Mediated Immune Protection Against BCR-ABL-Induced Leukemia Requires the CCL6 and CCL9 Chemokines. Blood (2009) 113(16):3813-20. doi: 10.1182/blood-2008-07-167189

67. Yi F, Jaffe R, Prochownik EV. The CCL6 Chemokine Is Differentially Regulated by C-Myc and L-Myc, and Promotes Tumorigenesis and Metastasis. Cancer Res (2003) 63(11):2923-32.
68. Lee HY, Hong IS. Double-Edged Sword of Mesenchymal Stem Cells: CancerPromoting Versus Therapeutic Potential. Cancer Sci (2017) 108(10):1939-46. doi: $10.1111 /$ cas. 13334

69. Ho IA, Toh HC, Ng WH, Teo YL, Guo CM, Hui KM, et al. Human Bone MarrowDerived Mesenchymal Stem Cells Suppress Human Glioma Growth Through Inhibition of Angiogenesis. Stem Cells (2013) 31(1):146-55. doi: 10.1002/stem.1247

70. Ohlsson LB, Varas L, Kjellman C, Edvardsen K, Lindvall M. Mesenchymal Progenitor Cell-Mediated Inhibition of Tumor Growth In Vivo and In Vitro in Gelatin Matrix. Exp Mol Pathol (2003) 75(3):248-55. doi: 10.1016/j.yexmp.2003.06.001

71. Shou P, Chen Q, Jiang J, Xu C, Zhang J, Zheng C, et al. Type I Interferons Exert Anti-Tumor Effect via Reversing Immunosuppression Mediated by Mesenchymal Stromal Cells. Oncogene (2016) 35(46):5953-62. doi: 10.1038/onc.2016.128

72. Bianchi G, Morandi F, Cilli M, Daga A, Bocelli-Tyndall C, Gambini C, et al. Close Interactions Between Mesenchymal Stem Cells and Neuroblastoma Cell Lines Lead to Tumor Growth Inhibition. PloS One (2012) 7(10):e48654. doi: 10.1371/journal.pone.0048654

73. Ling X, Marini F, Konopleva M, Schober W, Shi Y, Burks J, et al. Mesenchymal Stem Cells Overexpressing IFN-Beta Inhibit Breast Cancer Growth and Metastases Through Stat3 Signaling in a Syngeneic Tumor Model. Cancer Microenviron (2010) 3(1):83-95. doi: 10.1007/s12307-010-0041-8

74. Rodini CO, Goncalves da Silva PB, Assoni AF, Carvalho VM, Okamoto OK. Mesenchymal Stem Cells Enhance Tumorigenic Properties of Human Glioblastoma Through Independent Cell-Cell Communication Mechanisms. Oncotarget (2018) 9(37):24766-77. doi: 10.18632/oncotarget.25346

75. Wang HH, Cui YL, Zaorsky NG, Lan J, Deng L, Zeng XL, et al. Mesenchymal Stem Cells Generate Pericytes to Promote Tumor Recurrence via Vasculogenesis After Stereotactic Body Radiation Therapy. Cancer Lett (2016) 375(2):349-59. doi: 10.1016/j.canlet.2016.02.033

76. Kabashima-Niibe A, Higuchi H, Takaishi H, Masugi Y, Matsuzaki Y, Mabuchi Y, et al. Mesenchymal Stem Cells Regulate Epithelial-Mesenchymal Transition and Tumor Progression of Pancreatic Cancer Cells. Cancer Sci (2013) 104 (2):157-64. doi: 10.1111/cas.12059

77. Jung Y, Kim JK, Shiozawa Y, Wang J, Mishra A, Joseph J, et al. Recruitment of Mesenchymal Stem Cells Into Prostate Tumours Promotes Metastasis. Nat Commun (2013) 4:1795. doi: 10.1038/ncomms2766

78. Ben Nasr M, Vergani A, Avruch J, Liu L, Kefaloyianni E, D’Addio F, et al. CoTransplantation of Autologous MSCs Delays Islet Allograft Rejection and Generates a Local Immunoprivileged Site. Acta Diabetol (2015) 52(5):917-27. doi: 10.1007/s00592-015-0735-y

79. Fiorina P, Jurewicz M, Augello A, Vergani A, Dada S, La Rosa S, et al. Immunomodulatory Function of Bone Marrow-Derived Mesenchymal Stem Cells in Experimental Autoimmune Type 1 Diabetes. J Immunol (2009) 183 (2):993-1004. doi: 10.4049/jimmunol.0900803

80. Rodriguez R, Rubio R, Masip M, Catalina P, Nieto A, de la Cueva T, et al. Loss of P53 Induces Tumorigenesis in P21-Deficient Mesenchymal Stem Cells. Neoplasia (2009) 11(4):397-407. doi: 10.1593/neo.81620

81. Miura Y, Gao Z, Miura M, Seo BM, Sonoyama W, Chen W, et al. Mesenchymal Stem Cell-Organized Bone Marrow Elements: An Alternative Hematopoietic Progenitor Resource. Stem Cells (2006) 24(11):2428-36. doi: 10.1634/stemcells.2006-0089.

Conflict of Interest: The authors declare that the research was conducted in the absence of any commercial or financial relationships that could be construed as a potential conflict of interest.

Publisher's Note: All claims expressed in this article are solely those of the authors and do not necessarily represent those of their affiliated organizations, or those of the publisher, the editors and the reviewers. Any product that may be evaluated in this article, or claim that may be made by its manufacturer, is not guaranteed or endorsed by the publisher.

Copyright (อ 2021 Marinescu, Preda, Neculachi, Rusu, Popescu and Burlacu. This is an open-access article distributed under the terms of the Creative Commons Attribution License (CC BY). The use, distribution or reproduction in other forums is permitted, provided the original author(s) and the copyright owner(s) are credited and that the original publication in this journal is cited, in accordance with accepted academic practice. No use, distribution or reproduction is permitted which does not comply with these terms. 